\title{
Scenarios for refurbishment of a hydropower plant equipped with Francis turbines
}

\author{
Sebastian Muntean ${ }^{1, *}$, Romeo Susan-Resiga ${ }^{2}$, Eberhard Göde ${ }^{3}$, Alexandru Baya ${ }^{2}$, Radu Terzi ${ }^{4}$, and Constantin Tîrşi ${ }^{4}$ \\ ${ }^{1}$ Romanian Academy - Timişoara Branch, Timişoara, Romania \\ ${ }^{2}$ Politehnica University Timişoara, Timişoara, Romania \\ 3 Stuttgart University, Stuttgart, Germany \\ ${ }^{4}$ S.C. Hidroelectrica S.A., Râmnicu Vâlcea Subsidiary, Râmnicu Vâlcea, Romania
}

\begin{abstract}
The energy market imposes new requirements in hydraulic turbines operation. Usually, the old hydraulic turbines are not designed to meet these new requirements. Therefore, the refurbished solutions for hydraulic turbines are expected to be robust and flexible in operation in order to regulate the grid. A methodology is developed for a hydropower plant equipped with Francis turbines. Firstly, the solution available in the hydropower plant is examined. Secondly, two new solutions are designed for the hydraulic passage available in situ. Next, several scenarios from peak load operation to wide range operation are investigated in order to asses the performance of each technical solution. Consequently, the performances are compared proving the best solution for hydropower plant refurbishment.
\end{abstract}

\section{Introduction}

Hydropower is the largest source of renewable energy. Modern hydraulic turbines are required to operate over a significantly wider range of regimes, extending quite far from the best efficiency point in order to meet the demand on the energy market. It is the most efficient way to generate electricity and/or to regulate grid. Therefore, the technical solutions in order to refurbish the old hydropower plants are challenging task [1-6]. The main constrains are revealed in limitations of the hydropower plant operation $[7,8]$.

In particular, for low-medium head Francis hydraulic turbines the shape of the efficiency hill chart is practically given by the steep increase in the draft tube losses at offdesign operating points [9]. The main reason why the efficiency of a turbine significantly drops when operating far from the best operating regime is that the inherent residual swirl at runner outlet [10] leads to large draft tube losses [11]. Although this phenomenon cannot be avoided, one can adjust the runner geometry such that a weighted-average hydraulic efficiency becomes as high as possible over a certain range of operating points.

When refurbishing a hydraulic turbine the draft tube remains unmodified due to economical reasons. As a result, the new runner should be the best match for the existing draft tube within a wide operating range. The refurbished solution has to meet the requirements imposed by the electrical grid together with technical constrains associated to each hydropower plant [12].

\footnotetext{
* e-mail: seby@acad-tim.tm.edu.ro
}

The paper presents a methodology for refurbishment of the hydropower plant. An old solution available in a hydropower plant equipped with Francis turbine is investigated in Section 2. Two new runners are designed taking into account the hydraulic passage available in the hydropower plant and the technical constrains imposed in service. A synopsis view on the new solutions against old one is presented. Section 3 compares the performance of the new solutions against old one taking into account several scenarios. The scenarios include a distribution of the operating regimes from peak load to wide range quantifying the gain. The conclusions are drawn in Section 4 .

\section{The old and new solutions for a Francis runner}

Five control regimes denoted from R1 to R5 are selected on a wide discharge range together with its weighted values based on Francis turbine operation during one decade (1999-2009), Figure 1. The red dots on the hill chart correspond to operating points recorded in situ from 1999 to 2009. Then, five control regimes are selected to collect these operating points. The first control regime $(\mathrm{R} 1)$ collects the operating points with discharge values lower than $35 \mathrm{~m}^{3} / \mathrm{s}$, the second one (R2) from $35 \mathrm{~m}^{3} / \mathrm{s}$ to $40 \mathrm{~m}^{3} / \mathrm{s}$, the third one (R3) from $40 \mathrm{~m}^{3} / \mathrm{s}$ to $45 \mathrm{~m}^{3} / \mathrm{s}$, the forth regime (R4) from $45 \mathrm{~m}^{3} / \mathrm{s}$ to $47.5 \mathrm{~m}^{3} / \mathrm{s}$ and last regime (R5) with discharge values larger than $47.5 \mathrm{~m}^{3} / \mathrm{s}$.

Figure 2 presents number of hours in service on each Francis turbine unit installed in the power plant during 1999-2009. As a result, total number of hours in service 


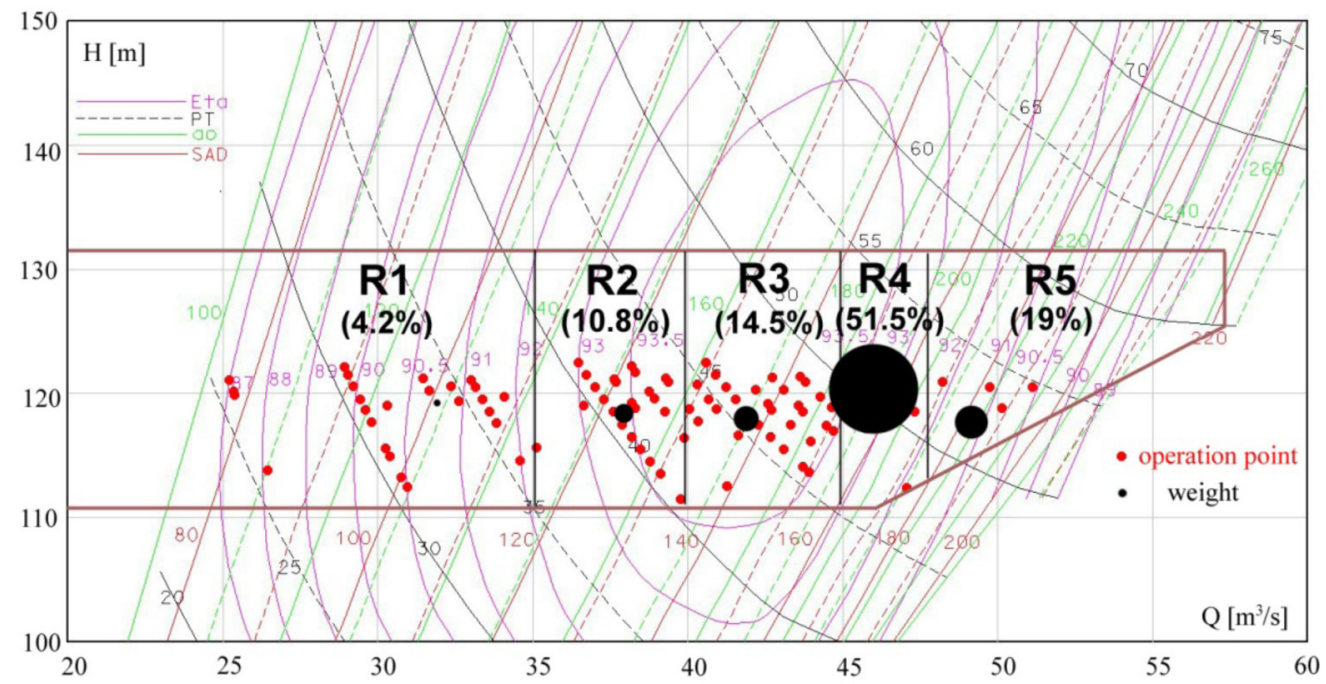

Fig. 1. Francis turbine hill chart together with five control regimes selected based on one decade operation (1999-2009) of both units available in the hydropower plant.

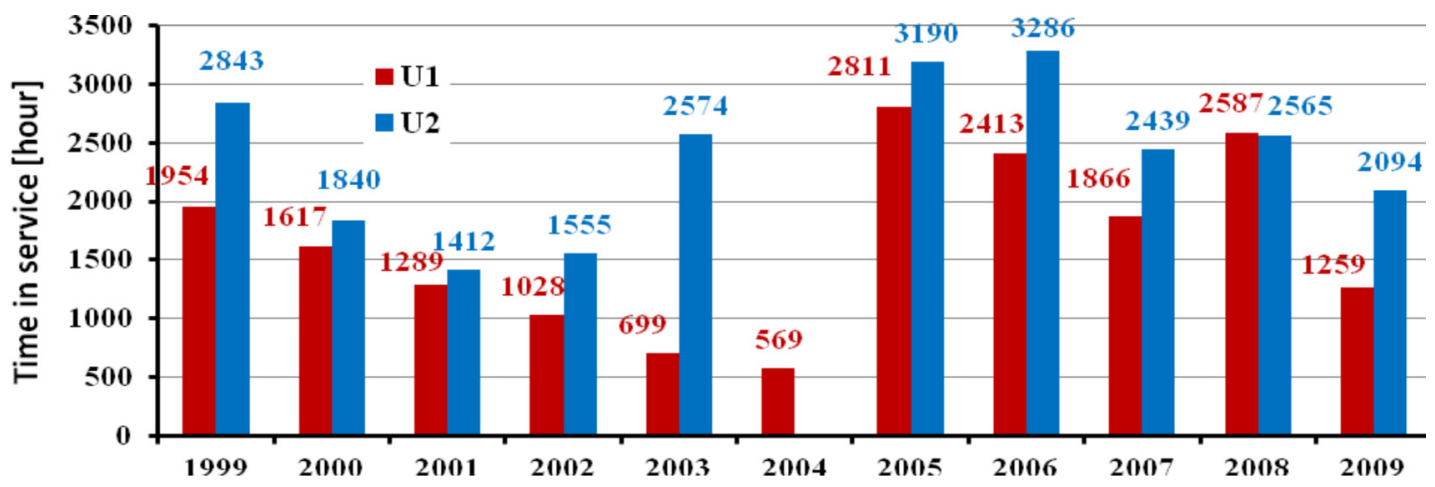

Fig. 2. Number of hours in service of the old Francis turbines units: U1 (red) and U2 (blue).

of 18,092 is counted for unit U1 while 23,798 h for unit U2, respectively. A weighted value is computed for each control regime as a ratio between cumulated number of hours in service associated to it and total number of hours. The weighted values are marked with black circles in Figure 1. The center of each black circle corresponds to the weighted average values of discharge and head computed using the operating points included in each control regime while it radius is proportional with the weight. One can see that around $76.8 \%$ of operating regimes (R2, R3 and R4) are clustered near to the best efficiency point revealing a peak operation. As a result, a synopsis view based on one decade operation of the existing Francis turbine is considered as reference value.

Two new Francis runners are designed for an existing hydraulic passage available in the hydropower plant, Figure 3. The new runner named V1 is designed together with Prof. Eberhard Göde using platform developed at Stuttgart University [13]. The second runner labeled $\mathrm{V} 2$ is developed starting from the previous one. The existing Francis runner available in the hydropower plant has 14 blades (denoted CHE with red) and new runners (V1 with blue and V2 with green) are designed with 17 blades. All solutions are investigated using three-dimensional fluid flow simulation [14] in seven operating points (from 0.7 to 1.2 of best efficiency point discharge) [15].

The normalized discharge and the dimensionless flux of moment of momentum quantities are defined [16] according to equation (1):

$$
Q^{*}=\frac{Q}{Q_{r e f}}, \quad m_{2} \equiv \frac{M_{2}}{\rho V_{r e f}^{3} \pi R_{r e f}^{2}},
$$

where $Q$ is the turbine discharge, $Q_{r e f}=42.5 \mathrm{~m}^{3} / \mathrm{s}$ the discharge value corresponding to the best efficiency point, $M_{2}$ the flux of moment of momentum at the runner outlet, $R_{\text {ref }}=1.1375 \mathrm{~m}$ the runner outlet radius and the transport velocity $V_{\text {ref }}=\Omega R_{\text {ref }}=44.67 \mathrm{~m} / \mathrm{s}$.

The dimensionless flux of moment of momentum at the runner outlet is computed based on numerical simulation flow and it is plotted in Figure 4a for each solution. One can observe smaller values for new runners than old one providing a lower level of the residual swirl that is ingested by the draft tube. The hydraulic efficiency over an extended operating range is shown in Figure $4 \mathrm{~b}$ for each solution computing the runner flow together with draft tube available in the hydropower plant [17-19]. 

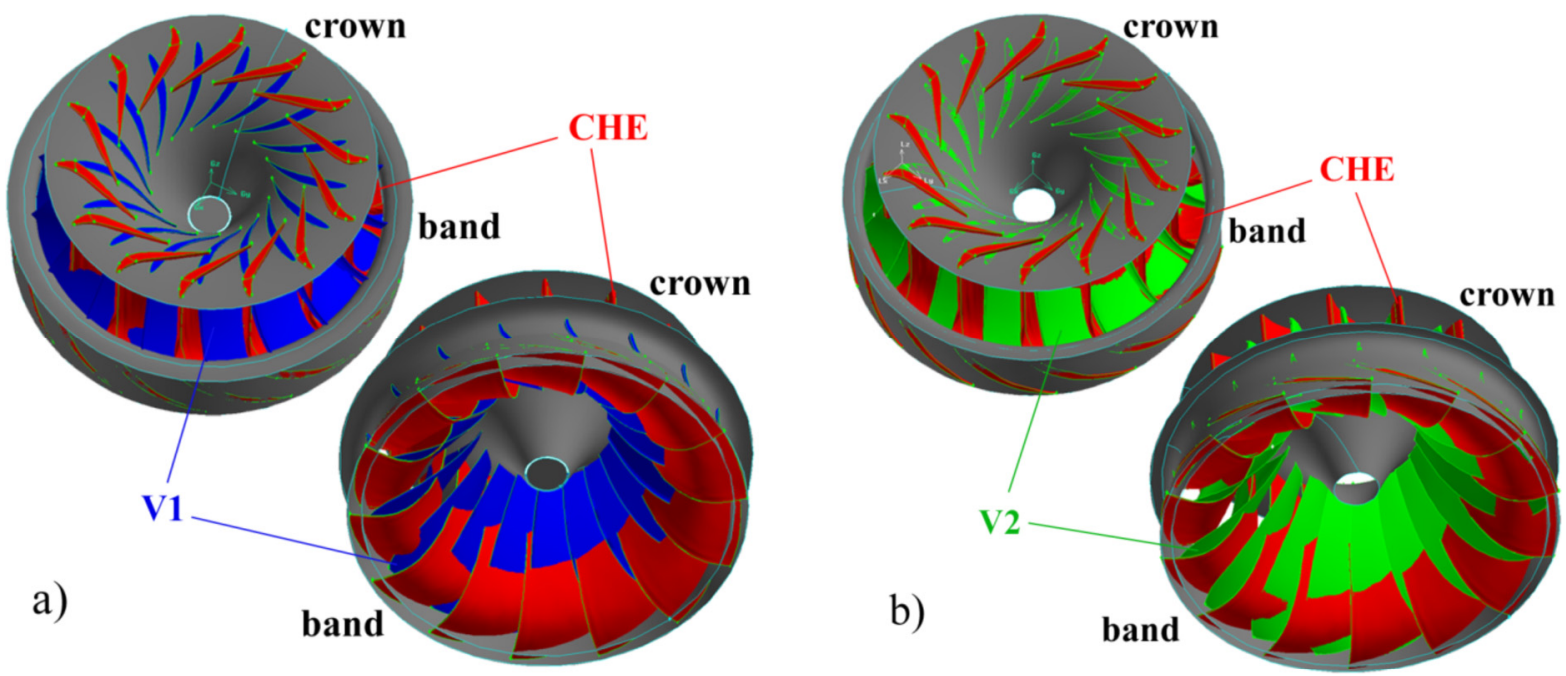

Fig. 3. New runner geometries with 17 blades against old runner geometry with 14 blades available in the hydropower plant (red): (a) V1 (blue) and (b) V2 (green).
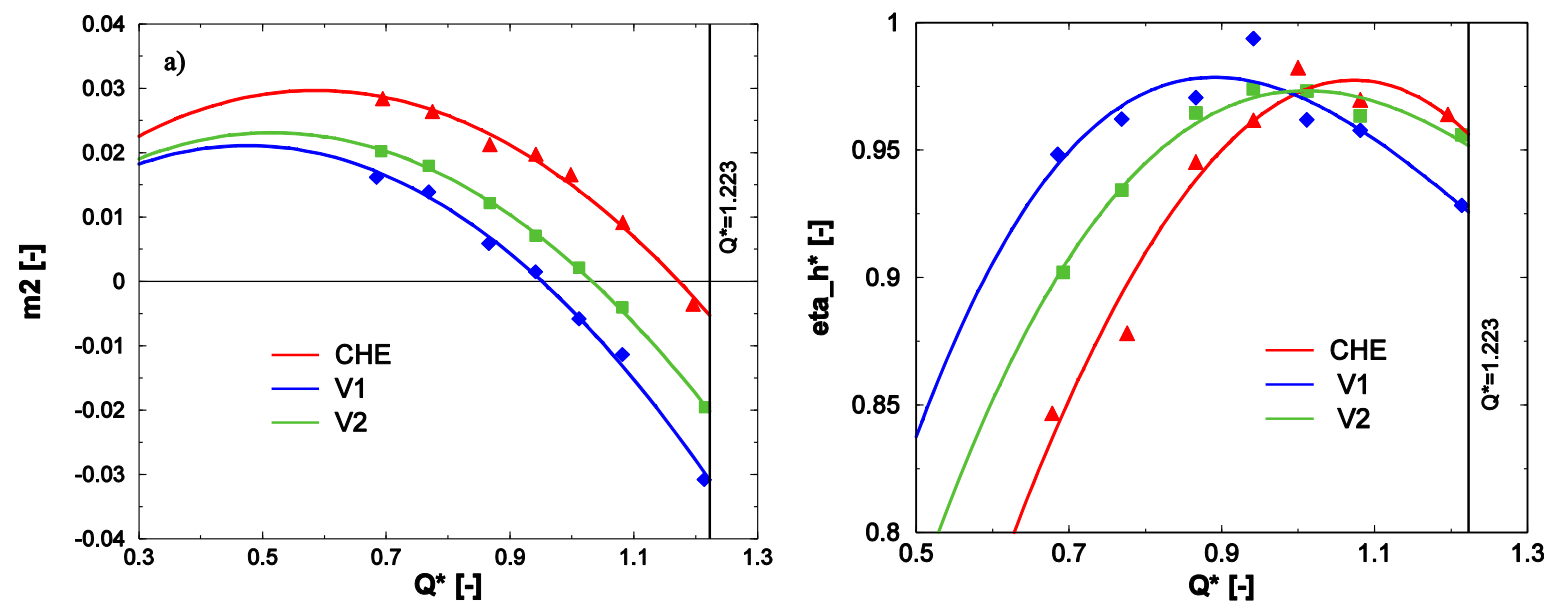

Fig. 4. (a) The dimensionless flux of moment of momentum $\left(m_{2}\right)$ versus the normalized discharge $\left(Q^{*}\right)$. (b) The hydraulic efficiency $\left(\eta_{h}^{*}\right)$ versus the normalized discharge $\left(Q^{*}\right)$.

A polynomial cubic fitting is applied to hydraulic efficiency $\left(\eta_{h}^{*}\right)$ for each solution against normalized discharge $\left(Q^{*}\right)$. The fitting parameters are included in Table 1 . The main constrain corresponds to the maximum normalized discharge of $Q^{*}=1.223$ due to the capacity of the tailrace tunnel. As a result, both new solutions are designed with best efficiency point location at lower discharge values than existing one.

Table 1. The hydraulic efficiency $\left(\eta_{h}^{*}\right)$ versus normalized discharge $\left(Q^{*}\right)$ for each solution.

\begin{tabular}{ll}
\hline & Polynomial cubic fitting equations \\
\hline CHE & $\eta_{h}^{*}=1.73821 Q^{*}-0.69318 Q^{* 2}-0.0725609 Q^{* 3}$ \\
V1 & $\eta_{h}^{*}=2.68918 Q^{*}-2.33751 Q^{* 2}+0.619441 Q^{* 3}$ \\
V2 & $\eta_{h}^{*}=2.32431 Q^{*}-1.74060 Q^{* 2}+0.389499 Q^{* 3}$ \\
\hline
\end{tabular}

The dimensional and dimensionless forms of the swirlfree velocity are defined in equation (2).

$$
\begin{aligned}
\frac{V_{z}}{\Omega R-V_{\theta}} & =\tan \beta_{2}=\frac{V_{s f}}{\Omega R} \Rightarrow V_{s f}=\frac{\Omega R V_{z}}{\Omega R-V_{\theta}}, \\
v_{s f} & =\frac{r v_{z}}{r-v_{\theta}} .
\end{aligned}
$$

The swirl-free velocity expresses the relative flow direction $\beta_{2}$ at the runner outlet, Figure 5a. It is a fictitious quantity associated with the velocity field. Locally, where the meridian velocity matches the swirl-free velocity the circumferential velocity vanishes. The swirl-free velocity profile practically remains unchanged at all operating points $[16,20]$ being unique for each runner. One can approximate the swirl-free velocity with a linear equation $v_{s f}=n+m q$ where $q$ is the discharge fraction. The $m$ coefficient is named slope while $n$ is average, respectively. The pair $(m=0$, $n=0.278$ ) is obtained based on numerical simulations for Francis runner available in the hydropower plant as shown in Figure 5b. The same values are yielded based on the 

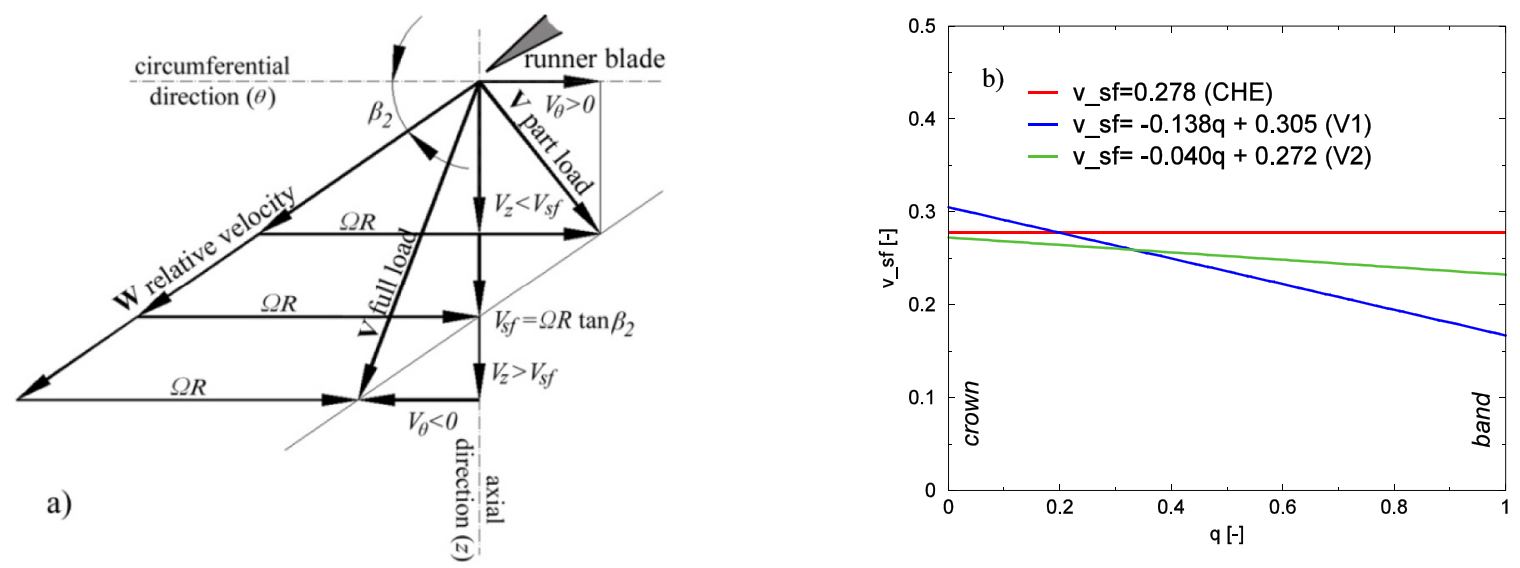

Fig. 5. (a) Swirl-free velocity definition. (b) Swirl-free velocity profile for each runner.
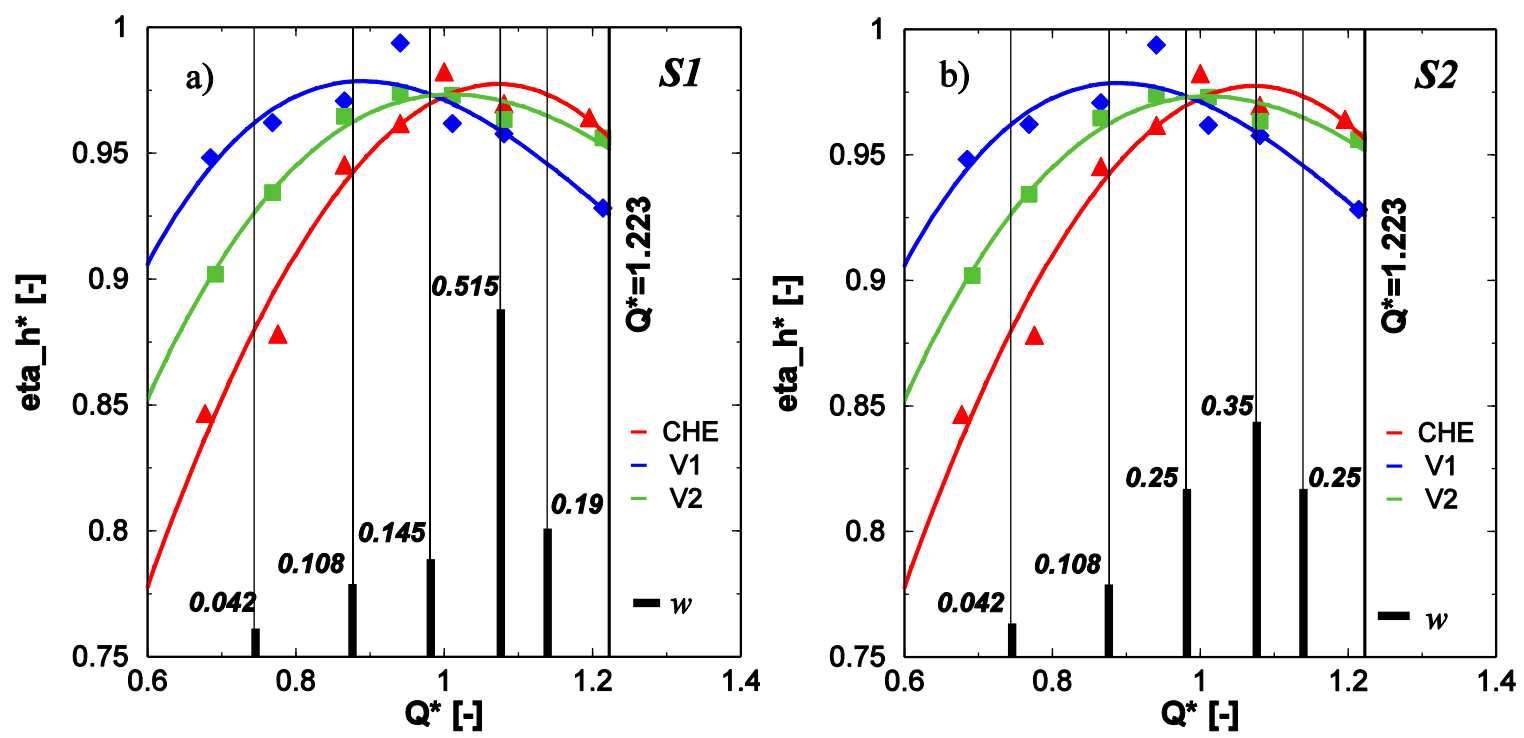

Fig. 6. The hydraulic efficiency $\left(\eta_{h}^{*}\right)$ versus the normalized discharge $\left(Q^{*}\right)$ and the weights associated to two scenarios: (a) scenario No. 1 (S1) and (b) scenario No. 2 (S2).

experimental data of the GAMM Francis model [20]. A constant swirl-free velocity profile corresponds to the classical design of the runner blades.

Both new runners are yielded with negative slope values $(m<0)$. As a result, both maxima of the hydraulic efficiency curves associated to the new runners are shifted toward lower discharge values than the solution available in the power plant, Figure 5b. This aspect was planned in the design stage due to the maximum discharge value imposed by the capacity of the tailrace tunnel.

\section{Scenarios for refurbishment of a Francis turbine}

The weighted efficiency is defined according to equation (3) in order to quantify the solution efficiency over a wide range [9].

$$
\eta^{*}=\sum_{i=\mathrm{R} 1}^{\mathrm{R} 5} w_{i}\left(\eta_{h}^{*}\right)_{i}[-],
$$

where $w$ is the weights associated to each operating regime and $\eta_{h}^{*}$ the hydraulic efficiency, respectively. The efficiency gain is introduced by equation (4) in order to quantify the deviation from existing solution. A new solution is better suited to the conditions than one installed into the hydropower plant when a positive value is obtained:

$$
\Delta \eta_{V_{i}}^{*}=\frac{\left(\eta_{V_{i}}^{*}-\eta_{\mathrm{CHE}}^{*}\right)}{\eta_{\mathrm{CHE}}^{*}} \times 100[\%], \quad i=1,2 .
$$

A first scenario labeled $S 1$ is built considering all technical solutions (old runner and new ones) in peak load operation, Figure 6a. In this scenario, the weights presented in Table 2 correspond to the regimes from R1 to R5 as in Figure 1. The efficiency gain values for both new solutions are negative meaning a more appropriate operation for existing solution in these conditions.

Other three scenarios are investigated for all three Francis runners considering different operating conditions from peak load to wide range. The hydropower plant operating 
Table 2. The hydraulic efficiency for each solution and the efficiency gain with respect to the existing one in scenario No. $1(S 1)$.

\begin{tabular}{lcccr}
\hline Scenario No. 1 $(S 1)$ & Weight $w_{i}[\%]$ & CHE & V1 & V2 \\
\hline Regime 1 (R1) & 4.2 & 0.880 & 0.962 & 0.926 \\
Regime 2 (R2) & 10.8 & 0.942 & 0.978 & 0.962 \\
Regime 3 (R3) & 14.5 & 0.970 & 0.973 & 0.973 \\
Regime 4 (R4) & 51.5 & 0.977 & 0.959 & 0.971 \\
Regime 5 (R5) & 19.0 & 0.973 & 0.946 & 0.965 \\
$\eta^{*}[-]$ & & 0.968 & 0.961 & 0.967 \\
$\Delta \eta^{*}[\%]$ & & -0.71 & -0.03 \\
\hline
\end{tabular}

Table 3. The weighted hydraulic efficiency for each solution and the efficiency gain with respect to the existing one in scenario No. 2 (S2).

\begin{tabular}{lccl}
\hline Scenario No. 2 (S2) & CHE & V1 & V2 \\
\hline$\eta^{*}[-]$ & 0.966 & 0.961 & 0.967 \\
$\Delta \eta^{*}[\%]$ & & -0.52 & 0.06 \\
\hline
\end{tabular}

conditions are modified based on distribution of weighted values associated to control operating regimes denoted $R_{i}$, $i=1,2, \ldots 5$. As a result, the second scenario $S 2$ keeps the same weights for regimes R1 and R2 as in scenario $S 1$ while the weights from regime R4 to regimes $\mathrm{R} 3$ and R5 are balanced as in Figure 6b. One can observe a redistribution of the weights as follow: $w_{\mathrm{R} 3}=w_{\mathrm{R} 5}=25 \%$ and $w_{\mathrm{R} 4}=35 \%$, respectively. The scenario $S 2$ corresponds to a peak load operation, too. However, the efficiency gain for second solution V2 becomes positive $\left(\Delta \eta^{*}=+0.06 \%\right)$ leading to the conclusion that V2 solution is an option for existing one (Tab. 3).

The weights in scenario No. 3 (S3) are redistributed between all regimes $\left(w_{\mathrm{R} 1}=14 \%, w_{\mathrm{R} 2}=17 \%, w_{\mathrm{R} 3}=w_{\mathrm{R} 5}=\right.$ $\left.22 \%, w_{\mathrm{R} 4}=25 \%\right)$, Figure $7 \mathrm{a}$. In this scenario, the operation time of the Francis turbine at part load conditions $\left(w_{\mathrm{R} 1}+\right.$ $w_{\mathrm{R} 2}=31 \%$ ) is larger than twice with respect to the scenario $S 1\left(w_{\mathrm{R} 1}+w_{\mathrm{R} 2}=15 \%\right)$. Both new solutions (V1 and V2) lead to positive values of efficiency gain being more appropriate to be selected for these operating conditions (Tab. 4).

The last scenario $(S$ ) $)$ takes into account a hypothetic case with equal weights for all regimes $\left(w_{i}=20 \%\right.$ with $i=\mathrm{R} 1 \ldots \mathrm{R} 5)$, Figure $7 \mathrm{~b}$. This scenario corresponds to an operation of the Francis turbine on an extended range. Clearly, both new solutions are more appropriate to be implemented for wide range operation than the existing one in the hydropower plant. However, the solution V1 fulfills better the operating conditions associated to an extended operating range (Tab. 5).

\section{Conclusions}

The paper presents a methodology for computing several scenarios to operate the Francis turbines. Firstly, the solution available in the hydropower plant is investigated together with in situ operating conditions. Five control regimes were defined based on hydraulic turbines operation during ten years. Secondly, two new Francis runners
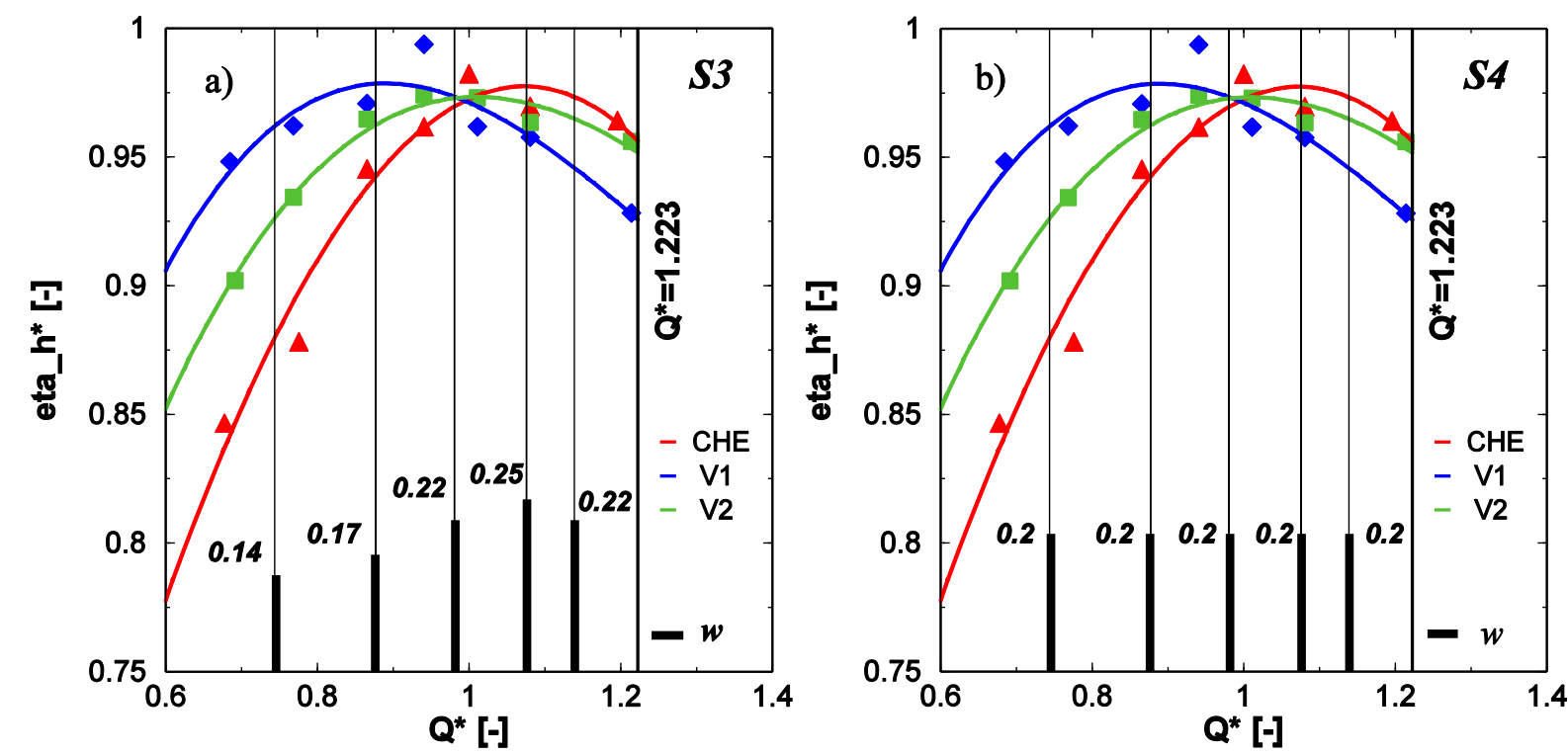

Fig. 7. The hydraulic efficiency $\left(\eta_{h}^{*}\right)$ versus the normalized discharge $\left(Q^{*}\right)$ and the weights associated to two scenarios: (a) scenario No. 3 (S3) and (b) scenario No. 4 (S4). 
Table 4. The weighted hydraulic efficiency for each solution and the efficiency gain with respect to the existing one in scenario No. 3 (S3).

\begin{tabular}{llll}
\hline Scenario No. 3 $($ S3) & CHE & V1 & V2 \\
\hline$\eta^{*}[-]$ & 0.955 & 0.963 & 0.962 \\
$\Delta \eta^{*}[\%]$ & & 0.82 & 0.75 \\
\hline
\end{tabular}

Table 5. The weighted hydraulic efficiency for each solution and the efficiency gain with respect to the existing one in scenario No. 4 (S4).

\begin{tabular}{llll}
\hline Scenario No. $4\left(S_{4}\right)$ & CHE & V1 & V2 \\
\hline$\eta^{*}[-]$ & 0.948 & 0.964 & 0.959 \\
$\Delta \eta^{*}[\%]$ & & 1.61 & 1.16 \\
\hline
\end{tabular}

were designed taking into account the geometric and hydraulic constrains associated to the hydropower plant. Next, the hydraulic efficiency curves are numerically computed for all solutions coupling the runners with the draft tube. The new runners investigated in the paper can be characterized as: (i) the best efficiency point is located at lower discharge values than existing one as it is planned in the design stage due to the limited capacity of the tailrace tunnel; (ii) the dimensionless flux of moment of momentum is smaller than the existing one. As a result, the new solutions deliver a lower level of the residual swirl at the draft tube inlet than the old runner; (iii) the dimensionless swirl-free profile reveals negative slope with respect to the constant profile obtained for old runner; and (iv) the hydraulic efficiency shows a flatness curve for each new runner than existing one. Consequently, the new solutions are better suited to operate on wide range than existing one due to the efficiency gain values are positive for scenarios $S_{3}$ and $S_{4}$.

This work has been supported by Romanian Ministry of National Education, CNCS-UEFISCDI, project no. PNII-ID-PCE-2012-40634 and by S.C. Hidroelectrica S.A., project no. 75/30.12.2010.

\section{References}

1. B. Papillon, J.-L. Gagne, S. Giroux, M. Sabourin, Turbine rehabilitation: Chute-des-Passes case study (HydroVision, Portland, Oregon, 2002)

2. M. Sallaberger, Ch. Michaud, H. Born, St. Winkler, M. Peron, Design and manufacturing of Francis Runners for Rehabilitation Projects (Hydro 2001, Riva del Garda, 2001)

3. J. Swiderski, J. Martin, High Power Francis runner-upgrade with a new design runner, Norcan Hydraulic Turbine Inc. Report, 1999
4. A.A. Sotnikov, Water turbines at Bratsk HES: design, use and upgrading, Hydrotech. Constr. 35, 507 (2001)

5. A.E. Lyutov, D.V. Chirkov, V.A. Skorospelov, P.A. Turuk, S. G. Cherny, Coupled multipoint shape optimization of runner and draft tube of hydraulic turbines, J. Fluids Eng.: Trans. ASME 137, 11 (2015)

6. J. Wu, K. Shimmei, K. Tani, K. Niikura, J. Sato, CFD-based design optimization for hydro turbines, J. Fluids Eng.: Trans. ASME 129, 159 (2007)

7. D. Frunzăverde, S. Muntean, G. Mărginean, V.C. Câmpian, L. Marşavina, Failure analysis of a Francis turbine runner, IOP Conf. Ser.: Earth Environ. Sci. 12, 012115 (2010)

8. A. Baya, S. Muntean, V.C. Câmpian, A. Cuzmoş, M. Diaconescu, Gh. Bălan, Experimental investigations of the unsteady flow in a Francis turbine draft tube cone, IOP Conf. Ser.: Earth Environ. Sci. 12, 012007 (2010)

9. R. Susan-Resiga, C. Ighişan, S. Muntean, A mathematical model for the swirling flow ingested by the draft tube of Francis turbines, Wasser Wirtshchaft Extra. 1, 23 (2015)

10. R. Susan-Resiga, G.D. Ciocan, I. Anton, F. Avellan, Analysis of the swirling flow downstream a Francis turbine runner, J. Fluids Eng.: Trans. ASME 128, 177 (2006)

11. T.C. Vu, S. Retieb, Accuracy assessment of current CFD tools to predict hydraulic turbine efficiency hill chart, in Proc. XXIst IAHR Symposium on Hydraulic Machinery and Systems, Lausanne, Switzerland (2002), Vol. 2, p. 193

12. A.A. Sotnikov, I.M. Pylev, Experience at Leningrad Metallurgical Plant with water turbines for use over wide ranges in head and load, Hydrotech. Const. 35, 73 (2001)

13. E. Göde, Performance upgrading of hydraulic machinery with the help of CFD (Notes on Numerical Fluid Mechanics and Multidisciplinary Design, 2992009), Vol. 100, p. 299

14. Fluent Inc.Fluent. User Guide V6.3 (2004)

15. S. Muntean, I. Ninaci, R. Susan-Resiga, A. Baya, I. Anton, Numerical analysis of the flow in the old Francis runner in order to define the refurbishment strategy, UPB Sci. Bul. Ser. D 72, 117 (2010)

16. R.F. Susan-Resiga, S. Muntean, F. Avellan, I. Anton, Mathematical modelling of swirling flow in hydraulic turbines for the full operating range, Appl. Math. Model. 35, 4759 (2011)

17. T. Ciocan, R. Susan-Resiga, S. Muntean, Improving draft tube hydrodynamics over a wide operating range, Proc. Roman. Acad. Ser. A 15, 182 (2014)

18. R.F. Susan-Resiga, S. Muntean, T. Ciocan, E. Joubarne, P. Leroy, L. Bornard, Influence of the velocity field at the inlet of a Francis turbine draft tube on performance over an operating range, IOP Conf. Ser.: Earth Environ. Sci. 15, 032008 (2012)

19. R.F. Susan-Resiga, S. Muntean, T. Ciocan, T. de Colombel, P. Leroy, Surrogate runner model for draft tube losses computation within a wide range of operating points, IOP Conf. Ser.: Earth Environ. Sci. 22, 012022 (2014)

20. T. Ciocan, R. Susan-Resiga, S. Muntean, Modelling and optimization of the velocity profiles at the draft tube inlet of a Francis turbine within an operating range, J. Hydraul. Res. 1, 74 (2016)

Cite this article as: Sebastian Muntean, Romeo Susan-Resiga, Eberhard Göde, Alexandru Baya, Radu Terzi, Constantin Tîrşi, Scenarios for refurbishment of a hydropower plant equipped with Francis turbines, Renew. Energy Environ. Sustain. 1, 30 (2016) 